\title{
LA POESÍA ELEVADA DESDE ABAJO. MARCIAL FRENTE A LA ÉPICA Y LA TRAGEDIA ${ }^{1}$
}

\author{
ANDRÉS GUTIÉRREZ TEMIÑO \\ Universidad de Oviedo \\ andresgutierreztemino@gmail.com \\ ORCID: 0000-0002-9387-7383
}

\section{RESUMEN}

Muchos son los estudios sobre la épica y la tragedia: estudios desde dentro, es decir, a partir de los eruditos y poetas. El poeta latino Marcial, en cambio, nos da en sus epigramas una razón humanista y realista de los escenarios, y así lo demuestra en epigramas programáticos como 1,$107 ; 4,49 ; 5,53 ; 8,3 ; 8,55 ; 9,50 ; 10,4 ; 11,90$ y 14, 1, entre otros. Un motivo de peso puede ser ensalzar el género del epigrama, en auge con el propio poeta, e intentar destacar; un segundo motivo puede ser que los géneros elevados colocan a dioses y héroes demasiado cerca del pueblo y se alejan de la realidad y de la vida cotidiana. Contra este tipo de poesía, Marcial nos enseña cuánta pedantería y vacuidad había en cada esquina donde se recitaba la épica.

Se da, pues, en Marcial un rechazo programático contra la poesía elevada de gran formato, oscura erudición y temática mitológica. Lo verdaderamente notable de Marcial es que rechaza la materia misma de la que se nutría la poesía elevada, el relato mitológico, y lo hace desde unos presupuestos exclusivamente literarios, volviendo la mira de su poesía hacia el hombre: hominem nostra pagina sapit $(10,4,10)$.

PALABRAS CLAVE: épica, tragedia, epigrama, mito, literatura latina, Marcial.

\section{THE HIGH POETRY FROM BELOW. MARTIAL AGAINST THE EPIC AND THE TRAGEDY}

\section{ABSTRACT}

There are many studies on epic and tragedy: studies from within, that is, from scholars and poets. The Latin poet Martial, on the other hand, gives us in his epigrams a humanistic and realistic reason for the scenarios, and this is demonstrated in programmatic epigrams such as 1,$107 ; 4,49 ; 5,53 ; 8,3 ; 8,55 ; 9,50 ; 10,4 ; 11,90$ and 14, 1, among others. A strong motive may be to extol the genre of the epigram, which is booming with the poet himself, and to try to stand out; a second reason may be that the high genres place gods and heroes too close to the people, away from reality and everyday life. Against this type of poetry, Martial teaches us how much pedantry and emptiness there was in every corner where the epic was recited.

There is, then, in Martial a programmatic rejection against elevated poetry of great format, dark erudition and mythological theme. What is really remarkable about Martial is that he rejects the very subject that high poetry was nourished by, the mythological story, and he does it from purely literary presuppositions, turning the focus of his poetry towards man: hominem nostra pagina sapit $(10,4,10)$.

KEYWORDS: epic, tragedy, epigram, myth, Latin literature, Martial.

\footnotetext{
${ }^{1}$ Quisiera agradecer a la profesora María del Carmen Hoces Sánchez (UGR) su ayuda en este trabajo.
} 


\section{VIS SCRIBAM THEBAS TROIAMVE MALASVE MYCENAS? $(\mathbf{1 4}, \mathbf{1}, \mathbf{1 1})$}

¿Cuál es ese diferente enfoque con el que puede mirar un autor de un género «menor», en este caso el epigrama, donde el filtro para hablar de la realidad es mucho más cristalino, sin tantos tapujos o trabas?

Bien es sabido que los géneros trágico y épico no son del agrado de Marcial, y así lo desarrolla a lo largo de su obra epigramática. Una razón de peso puede ser realzar el género del epigrama, que empieza a estar en auge con el bilbilitano, y destacar a la par que la tragedia y la épica, tan en boga en el siglo Id.C.; otra, el hecho de que coloca a los dioses y héroes demasiado cerca del pueblo y se aleja de la realidad y de la vida cotidiana, de lo importante. El héroe del epigrama es el hombre de carne y hueso.

\section{SCRIBIT IN AVERSA PICENS EPIGRAMMATA CHARTA $(\mathbf{8}, \mathbf{6 2}, \mathbf{1})$}

Marcial se ganó la vida en la urbe como cliente de diversos patronos, ${ }^{2}$ una vida sencilla y sin pretensiones que le permitía escribir libros de epigramas. Ser cliente implicaba convivir con otros poetas para ganarse la benevolencia de su patrono. De aquí sus ataques a Publio Papinio Estacio, ${ }^{3}$ por ejemplo, que componía obras épicas de gran extensión, y con quien rivalizaba. La poesía de Marcial, en cambio, pretendía ser sencilla y humana, natural y humilde, pero con una gran complejidad.

Marcial elige el epigrama, un género en aquel entonces menor, lo que implica crear manifiestos poéticos que lo defiendan frente a otros géneros más en boga, como la épica y la tragedia. El epigrama es un género difícil de tomar en serio, pero Marcial insiste en que también tiene su trasfondo ${ }^{4}$ tanto estético como poético $\mathrm{y}$, de este modo, compone poemas programáticos en los que reflexiona sobre la naturaleza de su poesía: la brevedad $(2,1)$, el tono distendido $(4,8 ; 9,20)$, la función social $(5,15)$, la inofensiva mordacidad $(5,15 ; 6,60)$ y el realismo $(8,3$; 10, 4). Del mismo modo, Marcial hace que el género epigramático no se reserve a unos pocos lectores elegidos y entendidos, sino que se dirija a un público amplio, al romano normal y corriente $(8,3 ; 10,3 ; 11,3 ; 12$, 2); es naturaleza misma del epigrama que se muestre como la antítesis de la épica y bien alejado también de la poesía bucólica y la poesía didáctica. ${ }^{5}$ Por lo tanto, el epigramista es cualquier cosa menos el poeta en su torre de marfil.

\footnotetext{
${ }^{2}$ Como Eliano, Lucio Domicio Apolinar, Faustino, Instante Rufo, Cayo Julio Próculo, Licinio Sura, Marcela, Marco Atelio Mélior, Marco Aquilino Régulo, Lucio Arruncio Estela, Lucio Estertino Avito, Terencio Prisco (vid. Moreno Soldevila, Fernández Valverde, Montero Cartelle 2005: 286-327). Dos de ellos, Estela y Mélior, fueron también patronos de su rival Estacio.

3 También cultivó la poesía de ocasión y convival.

4 Fitzgerald (2007: 1).

${ }^{5}$ Muñoz Jiménez (1994: 106-107).
} 
Hay tres epigramas que no pueden ser ignorados en una reconstrucción de la actitud con la que Marcial coloca su vocación artística dentro de la poesía de la era post augustal. En dos de ellos, que sirven para delinear el tipo de poeta que no quiere ser, Marcial se especializa en una controversia que invierte los contenidos de la poesía contemporánea, en el primer caso $(10,4)$, y las elecciones formales, el estilo hinchado y rimbombante con el que se intentó renovar la desgastada repetición del mito y el poco beneficio para la construcción positiva del ideal poético de Marcial, en el segundo $(4,49)$. Es, en cambio, el epigrama 8, 3 el que permite comprobar cómo, detrás de una ironía y autoironía alternativas, parodia y autoparodia, se esconde no solo una sincera vocación poética, sino también una gran seriedad de compromiso artístico. ${ }^{6}$ Marcial sabe cómo atacar los géneros predominantes y elevar el carácter menor de su campo: no ataca gratuitamente.

En cuanto a la métrica, frente a la rica variedad de versos en los epigramas, el género épico se enquista en la única vieja forma del hexámetro y se presenta como un largo carmen continuum, al contrario del epigrama, breue uiuidumque carmen $(12,61,1)$, distinguido, pues, por la breuitas. La defensa del epigrama largo - con el cual Marcial fuerza los límites canónicos del género, intentando ampliar sus potencialidades expresivas - está representada por la reflexión teórica sobre el criterio de longitud y brevedad $(2,77)$ y por un ingenioso monodístico $(1,110){ }^{7}$ Marcial es capaz de componer largos epigramas para atacar las grandes obras épico-trágicas.

Respecto a los personajes, se observa que los protagonistas se diferencian totalmente en los géneros elevados (héroes poderosos, audaces y valientes, dioses omnipotentes) de los géneros humildes (personajes cotidianos, el hombre del día a día, personajes cómicos y dignos de compasión). Del mismo modo, el tono se diferencia: frente a la musa grauis que inspira el género épico se muestra la musa tenuis del epigrama, cuya función principal es la diversión, sin preocupación por crear modelos de moral y de virtud. ${ }^{8}$ Que sea el último género en el rango no impide a Marcial poder elevar a la altura de la épica y la tragedia el epigrama, al que inculca su propio matiz latino, distinto al griego. Así pues, no se considera un poeta menor, ni cree estar cultivando una obra menor; a lo largo de sus composiciones, forja un programa poético de mucha coherencia, confianza y fuerza, a pesar de escribir nugae y ioci, con la reivindicación del epigrama y de la poesía humana.

En la Edad de Plata, la pérdida del mecenazgo de la cultura hace al autor abrirse y dirigir su poesía hacia un público amplio: aunque hay aún algunos epigramas laudatorios y dedicados a patronos y al emperador, el autor ya no tiene que dedicar obligatoriamente los poemas a sus promotores, sino que

\footnotetext{
${ }^{6}$ Sergi (1987: 376-377).

${ }^{7}$ Fusi (2009: 720).

8 Muñoz Jiménez (1994: 109).
} 
vocifera al pueblo para que le reconozca su mérito. El público es el juez que determina la producción artística de Marcial, que, para satisfacer su gusto, compone una poesía de entretenimiento, aunque no banal, de calidad literaria notable, aunque no inaccesible, y que, sobre todo, ofrece una visión divertida, aunque no conformista, de la vida real. ${ }^{9}$

Pero el caso es que los epigramas ni son tan populares ni tan accesibles en su entendimiento como se pueda pensar a poco que se pare en que las alusiones literarias y de civilización que incorpora de manera habitual requieren de un lector con un nivel elevado de formación. Así pues, Marcial aspira también a un público más selecto y culto, no en todas sus composiciones, pero sí en una parte de su poesía epigramática que desea que sea equiparada a la de los grandes autores y, sobre todo, que supera la poesía seria contemporánea $(4,49)$. Su obra no es, por lo tanto, una concatenación de epigramas sin sentido: el poeta ofrece un engranaje complicado con una gran intertextualidad, pues el lector medio es el intelectual de clase alta que tiene otium para poder leer libros sin problemas y que conoce tan bien la literatura griega contemporánea y pasada como el canon literario latino (Virgilio, Catulo, Ovidio, Propercio, etc.). ${ }^{10}$ Marcial subvierte el gusto de su época y la crítica: no a todo el mundo le agrada la poesía predominante. Marcial toma la figura del maestro y le reprocha el promover y perpetuar una literatura epigonal, negando la cabida en la escuela a formas más vitales de literatura $(8,3,13-16)$, y también le recrimina la enseñanza de mitología y del lenguaje pomposo, en vez del latine loqui que él promulga (1, Prol., 12).

\section{ET DOLET AVERSO QVOD FACIT ILLA DEO $(8,62,2)$}

Marcial quiere alzar la consideración del epigrama y por ello no ve problema en polemizar provocadoramente contra los géneros ya elevados y predominantes, la épica y la tragedia. Las referencias a ellos tienen un doble objetivo: por una parte, el rechazo y la crítica de la poesía épica contemporánea sirve como contraste de su proyecto poético, que queda, así, presentado por antítesis; por otra parte, épica y tragedia sirven como punto de referencia, esto es, marcan el nivel literario del que se parte - afirmación, con frecuencia, no exenta de falsa modestia - y que se aspira a alcanzar. ${ }^{11}$ El ataque a estos dos géneros, de hecho, forma parte de su programa y se convierte en un claro blanco de sus críticas: los temas alejados de la realidad, como la mitología, y dirigidos a unos lectores sumamente cultos.

Otro motivo para despreciar estos géneros es la enemistad con su contemporáneo Estacio, poeta épico con quien rivalizaría por conseguir el favor de los patronos literarios. Estacio no solo se adhirió al campo epigramista que

\footnotetext{
${ }^{9}$ Citroni (1990: 88).

${ }^{10}$ Sapsford (2012: 228).

${ }^{11}$ Beltrán (2005: 159).
} 
Marcial sin duda consideró suyo, sino que también se dirigió a los clientes a los que Marcial había estado cortejando durante varios años. ${ }^{12}$ Además, pudo haber entre ellos una incompatibilidad de caracteres: Estacio es un griego nacido en Nápoles, Marcial un romano de Hispania; ${ }^{13}$ y conociendo la latente xenofobia o fuerte romanitas que tenía el hispano para con los griegos, es entendible esta hostilidad mutua.

El bilbilitano paga con la misma moneda a las críticas que, desde los presupuestos poéticos canonizados por la tradición, iban dirigidas contra sus epigramas. Resulta, pues, que el género inmoral no es el epigrama, sino los grandes géneros elevados que tratan el mismo tema trillado de siempre. Marcial da la vuelta a la crítica tradicional y señala que no es el ingenuo epigrama sino la épica y la tragedia las que carecen de seriedad moral y literaria. Entonces, el autor de poesía elevada se entretiene más y ludit magis $(4,49,3)$ que aquel que compone epigramas, dotado de una dignidad y una ética que posibilitan que el fino caramillo venza las trompetas épicas $(8,3,21-22) .{ }^{14}$ La coherencia del epigramista reside más en una perspectiva moral: ataca la mitología en nombre propio, no en nombre de las teorías literarias. Los epigramas 4, 49 y 10, 4 son dos claros programas contra la mitología, en que Marcial encuentra una base moral vanidosa. Estos dos epigramas son manifiestos del realismo: en ellos se desarrolla su ataque a la poesía mitológica, no por su contenido, sino por su inutilidad frente a la vida real. Crea una polémica más moral que literaria. Marcial se da cuenta de las vacías ampulosidades y del alejamiento de lo esencial de la épica y la tragedia, e intenta sacar partido de la baja condición de su género: no cuenta historias de héroes y dioses, sino la vida que su público puede experimentar. Esta es su poética: escribir lo que vive y siente el lector. Y no solo el lector romano, sino el lector universal de cualquier tiempo.

En una breve ojeada a sus libros, se ve cuán importante es el mito en Marcial y cómo aparece por doquier, aunque $-\mathrm{y}$ he aquí un punto clave en su programa poético - no condena la mitología en sí, sino su uso. No puede escapar de ella: la mitología es la regla en toda la poesía latina y constituye su medio privilegiado de expresión, así como en la cultura antigua y en las escuelas. Lo que juzga es su inutilidad, y arremete en perfecta coherencia consigo mismo: ni la mitología ni ninguna esfera cultural están libres de esta inutilidad. No todos los epigramas comparten el programa moral del tardío 10, 4 (fue compuesto en 95, pero reeditado en 98), pero nunca se encuentra en ellos - y eso se opone de hecho a la epopeya (es decir, a Estacio), o a la tragedia - un nombre cultural que no tenga un papel textual, ya sea halagador, satírico o poético. ${ }^{15}$ Marcial reclama para su poesía un claro valor social frente a las composiciones mitológicas ${ }^{16} \mathrm{y}$, por ello, su continuo uso del mito estriba en rebajar a los dioses a la altura de los mortales: los baja a la calle y se ayuda

\footnotetext{
12 Henriksén (2012: 218-219).

13 Wolff (2008: 18).

${ }^{14}$ Citroni (1968: 276).

15 Vallat (2008: 164-165).

${ }_{16}$ Muth (1976: 201).
} 
de ellos para hacer juegos, bromas, comparaciones con sus conciudadanos. Marcial ha de tener maestría y un gran bagaje cultural para apropiarse de ecos de diferentes autores (Virgilio, Horacio, Ovidio, Catulo, etc.) y modelarlos para convertirlos en burla o en alabanza con su firma personal.

También la crítica a la poesía elevada tradicional se fundamenta en el estilo que utiliza $(4,49,7-8)$. El lenguaje que reivindica Marcial es el propio de la vida cotidiana romana $(8,3,19-20)$ : la lasciua uerborum ueritas, el latine loqui (1, Prol., 8 y 12). Llega incluso a afirmar que la poesía docta necesita un gramático que la explique para ser entendida $(10,21)$. Esta aproximación del epigramista a la realidad, al contrario que la poesía elevada y ampulosa, le da un matiz moral. El marco temático del día a día le brinda un gran abanico de posibilidades literarias para plasmar artísticamente cada experiencia de la vida cotidiana $(10,4,8) .{ }^{17}$ Así, Marcial se permite adaptar los diferentes gustos de su lector, el gran público, para que se vea más identificado. Su poesía pretende ser un reflejo de la vida cotidiana, como el tumulto de la gente por las calles, los malos y buenos olores, los colores de las ropas, los ruidos de la urbe... Si bien no se trata de una imagen fiel, le interesa destacar esos aspectos curiosos, contradictorios y sorprendentes de la realidad: no se limita a ser un retratista, sino que deforma esta realidad romana como un espejo y devuelve un reflejo humorístico y esperpéntico. ${ }^{18}$ En el prefacio del libro 12, se queja de la poca inspiración que tiene en Bílbilis y de la prouinciali solitudine (v. 4), no porque allí no haya vicios ni personajes corruptos y risibles, sino porque Roma está más caricaturizada con su muchedumbre y porque echa de menos el auditorio de la ciudad (v. 7). Si bien su idea antimitológica lo lleva a elogiar el campo con una filosofía estoica y tópicos como el beatus ille y el carpe diem y a rechazar la vida de la urbe, Marcial necesita de la ciudad y los mitos.

\section{SED MARCVS NON DOLET}

A lo largo de sus libros, Marcial desarrolla un rechazo programático hacia la poesía elevada de grandes dimensiones, erudita hasta la pedantería y de temática mitológica; y lo hace desde su posición literaria como autor de un género menor. Cierto es que el argumento mitológico había venido siendo desaprobado por poetas como Lucano y Persio, pero esta repulsa era resultado de una actitud moral: la reprensión de una cultura oficial, en el caso de Lucano, y la de un mundo ficticio en beneficio de la realidad, en el de Persio. En cambio, en Marcial la polémica antimitológica no es resultado de una actitud moralizante, sino el reconocimiento de la vacuidad de este material y su sustitución por una temática de lo real. ${ }^{19} \mathrm{Ni}$ el estudiante en la escuela ni el hombre cotidiano van a tener que enfrentarse a dioses

\footnotetext{
17 Beltrán (2005: 170).

${ }^{18}$ Citroni (1989: 337).

${ }^{19}$ Citroni (1968: 278-280).
} 
y monstruos mitológicos, pero sí al cazador de testamentos, al avaro y a la vieja lasciva que menciona Marcial en su obra.

Frente a los episodios mitológicos, épicos y trágicos, admirados por los literatos pretenciosos y tan alejados de la realidad que vienen a convertirse en despropósitos, el punto de mira del epigrama es el hombre y la vida cotidiana: se trata, pues, de una poética de lo real $(10,4) .{ }^{20}$ Marcial eleva el epigrama hasta convertirlo en un género capaz de rivalizar con la gran poesía aristocrática del siglo I d.C. Lo que hace es una labor titánica, una labor hercúlea: no toma un género ya aceptado y sigue la corriente dominante, sino que crea un nuevo tipo de poesía, con su programa y bases literarias propias, contrarios al gusto preponderante en literatura y, por ende, marginales y mal vistos. Sin embargo, que cree un nuevo género poético y arremeta contra la mitología no obsta para que no utilice en sus epigramas el mito, código estilístico común a todos los géneros literarios. ${ }^{21} \mathrm{De}$ hecho, es un motivo muy recurrente, aunque con un fin distinto al de la poesía culta: Marcial hace referencia a los dioses para denotar cualquier elemento cotidiano. Szelest (1974) sistematiza este uso del mito señalando que hay un simbolismo paródico en el que la confrontación con la realidad depara burlas y, por tanto, Marcial desmiente el nutriente mitológico. También cumple en ocasiones su función paradigmática. Habría que incluir un empleo neutro, cuando el mito forma parte de figuras de estilo (metonimia, metáfora, etc.). Otro uso del mito es decorar, aclarar, ilustrar o enfatizar un tema ${ }^{22}$ para que el lector lo entienda, pues este código mitológico es conocido por todo romano.

El éxito de Marcial es muestra de la personalidad literaria del autor, de su fuerza creadora, sincera y humana. Crea una ficción poética auténtica y equiparable a los grandes géneros: se convierte a sí mismo en un héroe épico (si bien, no protagonista de hexámetros dactílicos), que combate contra grandes monstruos mitológicos y sale vencedor. No se queja de que escribe con los dioses en contra $(8,62)$. Al final de su vida se retira a Hispania con el deber hecho, habiendo abierto caminos para nuevas vías literarias de temática humana.

Exista o no frustración por el estilo elegido y haya o no enfrentamientos con otros poetas líricos de la época, al parecer por envidia de Marcial, lo cierto es que el poeta ha sobrevivido sin ayuda de los dioses. No sabemos si el bilbilitano creía en los dioses o no, ni si era aficionado al teatro o a escuchar episodios épicos en los banquetes. Lo que sí sabemos es lo que nos ha dejado escrito: el epigramista hace ver que la conducta de los mitos resultaría inadmisible en la sociedad humana con el gran catálogo de ejemplos negativos que hemos visto a lo largo de los epigramas comentados; por lo tanto, Marcial desmitifica los mitos y, por consiguiente, la tragedia y la épica.

\footnotetext{
${ }^{20}$ Muñoz Jiménez (1994: 108).

${ }^{21}$ Wolff (2008: 39).

${ }^{22}$ Allen et al. (1970: 356).
} 


\section{BIBLIOGRAFÍA}

Allen, W. et al. (1970), «Martial: Knight, Publisher, and Poet», CJ, 65 (8), 345-357.

Beltrán, J. A. (2005), "Claves de la poética de Marcial», en Marco Valerio Marcial: Actualización científica y bibliográfica. Tres décadas de estudios sobre Marcial (19712000), Beltrán, J. A., Encuentra, A. P. et al. (eds.), Zaragoza, Universidad de Zaragoza, 151-219.

Citroni, M. (1968), «Motivi di polemica letteraria negli epigrammi di Marziale», DArch, 2, 259-301.

CITRONI, M. (1989), «Musa pedestre», en Lo spazio letterario di Roma antica I: La produzione del testo, Cavallo, G., Fedeli, P. y Giardina, A. (dirs.), Roma, Salerno, 311-341.

CITRONI, M. (1990), «I destinatari contemporanei», en Lo spazio letterario di Roma antica III: La rizecione del testo, Cavallo, G., Fedeli, P. y Giardina, A. (dirs.), Roma, Salerno, 53116.

FITZGERALD, W. (2007), Martial: The World of the Epigram, Chicago-Londres, University of Chicago.

FUSI, A. (2009), «La musa epigrammatica di Marziale», en Lo spazio letterario di Roma antica VI: I testi: 1. La poesia, Parroni, P. (dir.), Roma, Salerno, 716-751.

HENRIKSÉN, C. (2012), A commentary on Martial: «Epigrams»Book 9, Oxford, Oxford University Press.

Moreno SoldeVila, R., Fernández VAlVERde, J. y MONTERO CARTElle, E. (2004-2005), Marcial. Epigramas, vols. I y II, Madrid, Alma Mater.

MuÑOZ JIMÉNEZ, Ma J. (1994), «La doble presencia de Virgilio en Marcial», Cuadernos de Filología Clásica: Estudios Latinos, 7, 105-132.

MuTH, R. (1976), «Martials Spiel mit dem ludus poeticus», en Studies in Greek, Italic and Indo-European Linguistics, Offered to L. R. Palmer, Davies, A. M. y Meid, W. (eds.), Innsbruck, Institut fur Sprachwissenschaft der Universität Innsbruck, 199-207.

SAPSFORD, F. M. (2012), The 'Epic' of Martial, tesis doctoral, Birmingham, University of Birmingham. Disponible en: <https://etheses.bham.ac.uk/id/eprint/3671/2/Sa psford_12_PhD.pdf $>$.

SERGI, E. (1987), «Parodia del poeta ispirato ed autoironia in Marziale (Epigramma VIII 3)», Atti della Academia Peloritana dei Pericolanti, 63, 375-381.

SZELEST, H. (1974), «Die Mythologie bei Martial», Eos, 62, 297-310.

VALlAT, D. (2008), Onomastique, culture et société dans les Épigrammes de Martial, Bruselas, Latomus.

WolfF, É. (2008), Martial ou l'apogée de l'épigramme, Rennes, Presses Universitaires. 